\title{
The Additive Effect of Glycine and other Amino Acids on the Induction of the L-Phase of Group A $\beta$-Haemolytic Strepto- cocci by Penicillin and D-Cycloserine
}

\author{
By M. F. MICHEL AND W. HIJMANS \\ Research Laboratories, Department of Rheumatology, University Hospital, \\ Leiden, The Netherlands
}

(Received 8 December 1959)

\begin{abstract}
SUMMARY
The ability of glycine to induce L-phase of bacteria did not apply to group A $\beta$-haemolytic streptococci. In the presence of penicillin, glycine in a bacterial inhibitory concentration had a notably additive L-phase inducing property for streptococci. Reasons are given to support the view that this activity of glycine is limited to the induction of L-phase growth. A sharp increase in the yield of L-phase colonies was also observed when serine, threonine, methionine or alanine were tested under similar conditions. When the effectiveness of the racemate and both the isomers of these amino acids was compared, the D-isomer was the active substance in most cases. In one strain, the L-inducing and bacterial inhibitory action of the racemate and both isomers of methionine was tested simultaneously. The yield of L-phase colonies was found to be inversely proportional to the effect of the different stereoisomers on bacterial growth.

D-Cycloserine had a weak L-inducing effect on group A streptococci, but the combined action of D-cycloserine and glycine or DL-serine was equal to that obtained with penicillin and the same amino acids. Propagation of these L-phase organisms was possible in the presence of $1 \%(\mathrm{w} / \mathrm{v})$ glycine and within a narrow range of concentrations of D-cycloserine. The additive effect of the amino acids cited towards penicillin and $\mathrm{D}$-cycloserine for the induction of $\mathrm{L}$-phase structures can be explained by the antibiotic property of high concentrations of glycine and some of the D-amino acids.
\end{abstract}

\section{INTRODUCTION}

The induction of the L-phase of Streptobacillus moniliformis by penicillin was first demonstrated by Pierce (1942). Since then, this substance has been used for the induction of the L-phase of many types of Gram-positive and Gram-negative bacteria. In addition to penicillin, a certain number of other agents appear to have L-inducing properties. Gordon \& Gordon (1943) described a peculiar action of glycine on organisms of the genus Vibrio. After the addition of $0.25 \%$ to $1.5 \%$ $(w / v)$ glycine, the bacteria became swollen and enlarged. At $2 \%$ this phenomenon ceased as a result of total growth inhibition. In the high range of active concentrations very few ordinary bacillary types were seen. The picture was mainly that of large circular forms, wherein signs of autolysis were also present. Maculla \& Cowles (1948) showed that high concentrations of glycine caused lysis of different 
organisms, whereas organisms adapted to high concentrations of this substance (Gordon, Hall \& Stickland, 1949) were insensitive to this action; their growth properties remained undisturbed. Dienes \& Weinberger (1951) obtained L-phases of bacteria from several species by using glycine, but penicillin was effective with many more species than was glycine. Dienes \& Zamecnik (1952) examined other amino acids for this effect. These substances were tested on strains of Salmonella typhimurium and Haemophilus influenzae. Both organisms produced L-colonies abundantly in the presence of glycine or penicillin. Positive results were also obtained with a few other amino acids; L-colonies developed with concentrations varying between $0 \cdot 5-3.0 \%(w / v)$ glycine, DL-methionine, L-phenylalanine and L-tryptophan. Glycine was the most effective amino acid.

Although the problem of the possible identity between L-phase growth and protoplasts will not be discussed here, these structures show enough similarities to justify mutual exchange of methods for isolation purposes. Welsch (1958) reported on protoplast formation with Escherichia coli exposed to pencillin or glycine as well as serine, alanine and $\alpha$-aminobutyric acid. Lark \& Lark (1958) obtained protoplastlike structures from Alkaligenes faecalis in the presence of certain D-amino acids. As cycloserine was reported by Ciak \& Hahn (1959) to induce protoplast formation in Escherichia coli, the study of this compound was also included in the present work. The use of the term protoplast by these authors may now need revision in the light of the suggestions by Brenner et al. (1958). Some of these forms could probably be classified as spheroplasts according to McQuillen (1959).

Having established that glycine alone was ineffective in any concentration between $\mathbf{0 . 2 5}$ and $3 \%$ in inducing the L-phase growth of group $\mathbf{A} \beta$-haemolytic streptococci, the effect of this substance was examined when incorporated in a medium suitable for growing L-structures of this species. It appeared then that glycine, and some other amino acids, either as the racemate, or especially as the $D$-isomer, markedly increased the yield of the L-phase colonies in the presence of penicillin or D-cycloserine.

\section{METHODS}

Organisms. All strains tested belonged to group A $\beta$-haemolytic streptococci. Strains AED (type 12), GL 8 (type 19), ADA (type 14), were obtained from Dr L. Dienes (Boston, U.S.A.), the other strains B1 (type 1), B4 (type 1), B6 (type 11.27.44), B7 (type 12), B8 (type 11.27.44), B9 (type 12), B14 (type 3), B17 (type 22), were of local origin. All strains except GL 8 and ADA were typed with the agglutination reaction.

Medium. The medium consisted of a tryptic digest of beef heart infusion with $1.3 \%(\mathrm{w} / \mathrm{v})$ agar. Before pouring the plates, horse serum previously inactivated at $56^{\circ}$ for $30 \mathrm{~min}$. and sodium chloride were added (final concentration $10 \%$ and $0.6 \mathrm{M}$ respectively). The final volume in each plate was $15 \mathrm{ml}$. This medium plus penicillin will be referred to as the basal medium.

Amino acids. The racemates and single isomers of serine, threonine, alanine and methionine (Hoffmann-La Roche), and glycine were made up in the maximum concentration. After autoclaving at $15 \mathrm{lb}$./sq.in. for $15 \mathrm{~min}$. $\left(121^{\circ}\right)$, amounts were added to the basal medium to final percentages ranging from 0.25 to $1.5 \%(\mathrm{w} / \mathrm{v})$ of the different substances tested. 
Antibiotics. The D-cycloserine used was the synthetic product (Hoffmann-La Roche). A solution containing $100 \mathrm{mg}$. $/ \mathrm{ml}$. was sterilized through a glass filter. A commercial preparation of the potassium salt of penicillin was used in a solution of 200,000 units $/ \mathrm{ml}$.

Induction of the L-phase. The technique used for isolation of the L-phase of group A $\beta$-haemolytic streptococci was that described by Sharp (1954). The plates were inoculated with a 14-16 hr. culture grown in glucose broth. After incubation for $1.5 \mathrm{hr}$. at $37^{\circ}$, three small troughs were cut in the centre of the agar and a quantity of the solutions equivalent to 400 units penicillin or $3 \cdot 0 \mathrm{mg}$. D-cycloserine, was deposited in each trough. The plates were then incubated for a week at $37^{\circ}$ semianaerobically by the Fortner (1928) method.

Dry weights. The evaluation of growth of the unmodified streptococcus strain B 1 in the presence of different concentrations of glycine was performed by measuring dry weights of bacteria after $48 \mathrm{hr}$. incubation in the same medium without the addition of agar, salt and penicillin. In this case the evaluation of bacterial growth by measuring dry weights was the only reliable method, because glycine gives rise to inhomogeneous granular suspensions (Gordon \& Gordon, 1943).

Turbidimetry. When the streptococcus strain AED was tested for the effect of the racemate or the single isomers of methionine, it showed homogeneous suspensions after growth. This permitted the evaluation of growth variations caused by the three substances as turbidity readings, using a Unicam Spectrophotometer at a wavelength of $550 \mathrm{~m} \mu$. The medium consisted of Heart Brain Infusion (Difco), enriched with $10 \%(\mathrm{v} / \mathrm{v})$ horse serum without added salt or penicillin.

Minimal inhibitory concentrations. The inhibitory effect of D-cycloserine on streptococcus strain AED was assessed by measuring the turbidities of the growth in a conventional dilution series ranging from 100 to $500 \mu \mathrm{g}$. D-cycloserine in glucose broth. The turbidities were read at $550 \mathrm{~m} \mu$ after incubation for $24 \mathrm{hr}$. at $37^{\circ}$.

Explanation of symbols. The number of $\mathrm{L}$-phase colonies in the basal medium was verified between 4-6 times for all strains, and ranged from just a few to several hundreds, depending on the strain tested. Reproducibility within each strain was satisfactory for the purposes of this study. The counting was done by means of a stereomicroscope, and was practicable up to 600 colonies/plate. Only the highest figure of each control series is recorded, and this figure is given between brackets. When the number of L-phase colonies exceeded 600 (which never occurred in the control series) this was registered with multiples of the + sign. The estimated number of L-phase colonies scored with ++ was between 600 and 1000; with +++ between 1000 and 4000 ; with ++++ over 4000 colonies.

\section{RESULTS}

All efforts to grow the L-phase of group A $\beta$-haemolytic streptococci with glycine as an inducing agent failed but it was found that the combined action of glycine and penicillin considerably enhanced the number of L-phase colonies as compared with that obtained with penicillin alone (Table 1 ). The $B 1$ strain tested under these conditions never gave more than $50 \mathrm{~L}$-phase colonies in many controls, whereas about 750 colonies were obtained when the medium contained $1 \cdot 25 \%(w / v)$ glycine. The L-inducing action of glycine, up to $1 \cdot 25 \%$, was roughly inversely proportional 
Table 1. Influence of increasing concentrations of glycine on the yield of L-phase colonies from a strain of group $\boldsymbol{A} \beta$-haemolytic streptococci on the basal medium, and on dry weights of the coccal form of the same strain grown in an identical medium without the addition of agar, penicillin and salt

$\begin{array}{cccc}\text { Slycine } & \begin{array}{c}\text { No. of } \\ \text { concentration } \\ \%(\mathbf{w} / \mathbf{v})\end{array} & \begin{array}{c}\text { L-phase } \\ \text { colonies }\end{array} & \begin{array}{c}\text { Dry weight } \\ \text { of bacteria } \\ \text { in mg./ml. }\end{array} \\ \text { B1 } & \text { Control } & 50 & 0.348 \\ & 0.5 & 28 & 0.323 \\ & 0.75 & 150 & 0.318 \\ & 1.0 & 500 & 0.263 \\ & 1.25 & 750 & 0.116 \\ & 1.5 & 200 & 0.063\end{array}$

The number of $L$-phase colonies obtained in many experiments with the $B 1$ strain on the basal medium never exceeded 50.

Table 2. Effect of the addition of varying concentrations of glycine or DL-serine to the basal medium on the yield of L-phase colonies in eight strains of group $A \beta$-haemolytic streptococci

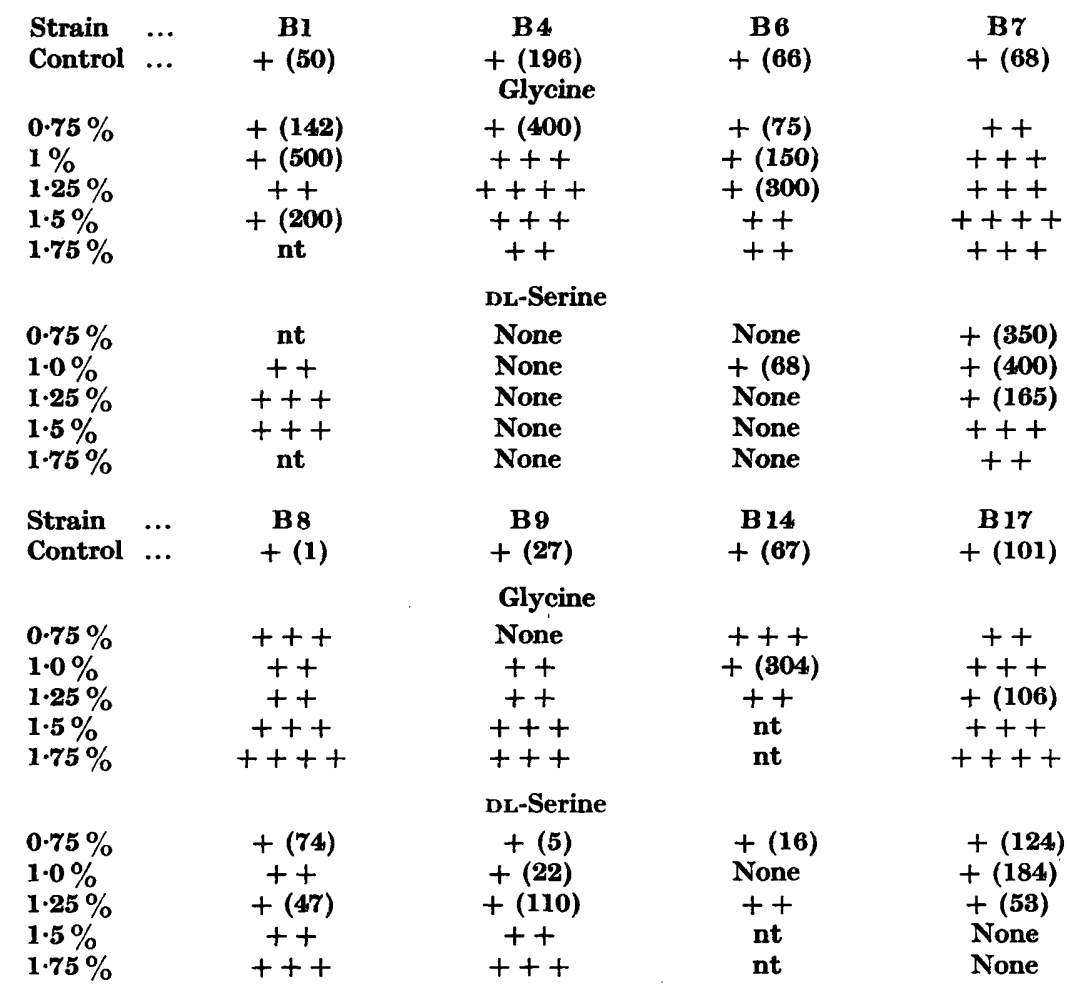

Figures between parentheses are exact numbers of $L$-phase colonies counted in the plate. The number of control plates for all strains varied from 4 to 6 . Only the highest figure of these is given here each time. Evaluation of colony numbers is expressed as: $+=0-600,++=600$ $1000, t+t=1000-4000, t++t=4000$ or more colonies. $n t=$ not tested. 
to its growth inhibitory effect, according to the dry weights of organisms harvested from media containing the different concentrations of amino acid.

To examine the effect of other amino acids DL-serine (structurally related to glycine) was selected. As early experiments gave results comparable with those obtained with glycine, eight strains were tested simultaneously for the effect of glycine or DL-serine (Table 2). The concentrations of the amino acids used were between 0.75 and $1.75 \%(w / v)$, the highest ones being tested only as far as necessary. High yields of L-phase colonies were obtained in all cases with glycine at 1.25-1.5\%. With DL-serine, the results were equally good with 5 strains (B1, B7, B8 and B 14) out of 8. Except for the B 1 strain, the effective concentration of this amino acid was found at 1.5-1.75\%. Three strains (B 4, B6, B 17) on the other hand, remained unaffected even when exposed to high concentrations of DL-serine.

Possible differences in activity as between the individual isomers of DL-serine and the racemate were then considered. Four strains (B6, AED, GL 8 and ADA) were tested in this respect, at concentrations varying between 0.25 and $1.5 \%$ (Table 3). It appeared that the additive L-phase inducing property of DL-serine toward penicillin, could be attributed in all the strains to the D-isomer. The Lisomer on the other hand, did not prevent the formation of L-phase colonies, even in the high range of concentrations in two out of the four strains (B6 and AED). It is to be noted that the B6 strain, which showed no influence of DL-serine at all, was favourably affected even by a concentration as low as $0.25 \%$ of $\mathrm{D}$-serine. The increase of the L-phase growth of strain B6 by D-serine is shown in Plate 1.

The experiments were repeated with the same strains under similar conditions but with the chemically related threonine in place of serine. The results (Table 4)

Table 3. Effect of the addition of varying concentrations of the racemate and both the isomers of serine on the yield of $L$-phase colonies in four strains of group $A \beta$-haemolytic streptococci

\begin{tabular}{|c|c|c|c|c|}
\hline Strain & & DL-Serine & L-Serine & D-Serine \\
\hline B6 & $\begin{array}{l}\text { Control } \\
0.25 \% \\
0.5 \% \\
1.0 \% \\
1.5 \%\end{array}$ & $\begin{array}{l}+(66) \\
\text { None } \\
\text { None } \\
\text { None } \\
\text { None }\end{array}$ & $\begin{array}{l}+(66) \\
+(1) \\
\text { None } \\
\text { None } \\
+(47)\end{array}$ & $\begin{array}{c}+(66) \\
+++ \\
+++ \\
++++ \\
++++\end{array}$ \\
\hline AED & $\begin{array}{l}\text { Control } \\
0.25 \% \\
0.5 \% \\
1.0 \% \\
1.5 \%\end{array}$ & $\begin{array}{c}+(600) \\
+++ \\
+++ \\
++++ \\
++++\end{array}$ & $\begin{array}{l}+(600) \\
+(180) \\
+(120) \\
+(68) \\
+(\mathbf{7 8})\end{array}$ & $\begin{array}{l}+(600) \\
+++ \\
+++ \\
++++ \\
++++\end{array}$ \\
\hline GL 8 & $\begin{array}{l}\text { Control } \\
\mathbf{0 . 2 5} \% \\
\mathbf{0 . 5} \% \\
\mathbf{1 . 0} \% \\
\mathbf{1 . 5} \%\end{array}$ & $\begin{array}{l}+(\mathbf{1 7 4}) \\
+(\mathbf{3}) \\
+(\mathbf{1 7}) \\
+(\mathbf{5 3}) \\
+++\end{array}$ & $\begin{array}{c}+(\mathbf{1 7 4}) \\
\text { None } \\
\text { None } \\
\text { None } \\
\text { None }\end{array}$ & $\begin{array}{c}+(\mathbf{1 7 4}) \\
+++ \\
+++ \\
++++ \\
++++\end{array}$ \\
\hline ADA & $\begin{array}{l}\text { Control } \\
0.25 \% \\
0.5 \% \\
1.0 \% \\
1.5 \%\end{array}$ & $\begin{array}{c}+(400) \\
+(8) \\
+(25) \\
+(8 \theta) \\
++\end{array}$ & $\begin{array}{l}+(400) \\
\text { None } \\
\text { None } \\
\text { None } \\
\text { None }\end{array}$ & $\begin{array}{c}+(400) \\
++ \\
+++ \\
++++ \\
+++\end{array}$ \\
\hline
\end{tabular}

The explanation of the symbols is given in Table 2. 
with threonine were on the whole similar to those obtained with serine, but the number of L-colonies of the $\mathbf{B} 6$ strain was increased by both the racemate and the single $\mathrm{D}$-isomer. The L-isomer moderately enhanced the number of L-phase colonies in the AED strain, but not in the three remaining strains.

Table 4. Effect of the addition of varying concentrations of the racemate and both the isomers of threonine on the yield of L-phase colonies in four strains of group $A \beta$ haemolytic streptococci

\begin{tabular}{|c|c|c|c|c|}
\hline Strain & & DL-Threonine & L-Threonine & D-Threonine \\
\hline B 6 & $\begin{array}{l}\text { Control } \\
0.25 \% \\
0.5 \% \\
1.0 \% \\
1.5 \%\end{array}$ & $\begin{array}{c}+(66) \\
\text { nt } \\
++ \\
+++ \\
+++\end{array}$ & $\begin{array}{c}+(\mathbf{6 6}) \\
\text { nt } \\
+(\mathbf{6 7 )} \\
+(\mathbf{5 5}) \\
+(\mathbf{1 7 5})\end{array}$ & $\begin{array}{c}+ \text { (66) } \\
\text { nt } \\
++ \\
+++ \\
+++\end{array}$ \\
\hline AED & $\begin{array}{l}\text { Control } \\
0.25 \% \\
0.5 \% \\
1 \cdot 0 \% \\
1 \cdot 5 \%\end{array}$ & $\begin{array}{l}+(600) \\
+++ \\
++ \\
++ \\
++\end{array}$ & $\begin{array}{c}+(600) \\
++ \\
++ \\
++ \\
++\end{array}$ & $\begin{array}{c}+(600) \\
+++ \\
++ \\
+++ \\
++++\end{array}$ \\
\hline GL 8 & $\begin{array}{l}\text { Control } \\
\mathbf{0 . 2 5} \% \\
\mathbf{0 . 5} \% \\
\mathbf{1 . 0} \% \\
\mathbf{1 . 5} \%\end{array}$ & $\begin{array}{c}+(\mathbf{1 7 4}) \\
++ \\
++ \\
++ \\
+++\end{array}$ & $\begin{array}{l}+(\mathbf{1 7 4}) \\
+(\mathbf{4 1}) \\
+(\mathbf{3 3}) \\
+(\mathbf{2 0}) \\
+(\mathbf{8 7})\end{array}$ & $\begin{array}{c}+(174) \\
++ \\
+++ \\
+++ \\
++++\end{array}$ \\
\hline ADA & $\begin{array}{l}\text { Control } \\
0.25 \% \\
0.5 \% \\
1.0 \% \\
1.5 \%\end{array}$ & $\begin{array}{c}+(400) \\
+(110) \\
++ \\
+++ \\
++\end{array}$ & $\begin{array}{l}+(400) \\
+(400) \\
+(175) \\
+(50) \\
+(80)\end{array}$ & $\begin{array}{c}+(\mathbf{4 0 0}) \\
+++ \\
+++ \\
++++ \\
+++\end{array}$ \\
\hline
\end{tabular}

The explanation of the symbols is given in Table 2.

Of the amino acids found in the cell walls of group A streptococci, namely alanine, lysine and glutamic acid (Salton, 1953; Cummins \& Harris, 1956; Hayashi \& Barkulis, 1959) only alanine was tested as the racemate and the isomers with four strains. Though a positive result was detected, the results (Table 5) were on the whole less marked than the previous ones. Strain B6 did not respond to the addition of DL-alanine; strain AED behaved as it did in the presence of L-threonine, i.e. a moderate increase in the number of L-phase colonies, and strain ADA reacted exclusively but weakly to the presence of the D-isomer.

The AED strain was tested with methionine, as the L-inducing property of its racemate was mentioned by Dienes \& Zamecnik (1952). The strain was also exposed to concentrations $(0 \cdot 125-1 \%, w / v)$ of the racemate and the isomers in a liquid medium without addition of penicillin and salt, in order to evaluate the effect of the various configurations of the amino acid on the growth of the organisms in the coccal form. The figures for L-phase colonies are given in Table 6, and the turbidimetric data evaluating bacterial growth in Fig. 1. It can be seen that in the presence of the racemate and the $\mathrm{D}$-isomer of methionine, high numbers of L-phase colonies arose, whereas only a few grew in the presence of the L-enantiomorph. On the other hand, the results with bacterial growth point to a reversed situation, i.e. the racemate and the $D$-isomer caused moderate and strong inhibition of growth 
Table 5. Effect of the addition of varying concentrations of the racemate and both the isomers of alanine on the yield of $L$-phase colonies in four strains of group $A \beta$-haemolytic streptococci

\begin{tabular}{|c|c|c|c|c|}
\hline Strain & & DL-Alanine & L-Alanine & D-Alanine \\
\hline B 6 & $\begin{array}{l}\text { Control } \\
0.25 \% \\
0.5 \% \\
1.0 \% \\
1.5 \%\end{array}$ & $\begin{array}{l}+(66) \\
+(130) \\
+(120) \\
+(210) \\
+(15)\end{array}$ & $\begin{array}{l}+(66) \\
+(130) \\
+(100) \\
+(58) \\
+(7)\end{array}$ & $\begin{array}{l}+(\mathbf{6 6}) \\
+(\mathbf{1 9 2}) \\
+(\mathbf{1 4 0 )} \\
+++ \\
+++\end{array}$ \\
\hline AED & $\begin{array}{l}\text { Control } \\
\mathbf{0 . 2 5} \% \\
\mathbf{0 . 5} \% \\
\mathbf{1 . 0} \% \\
\mathbf{1 . 5} \%\end{array}$ & $\begin{array}{c}+(600) \\
++ \\
+++ \\
+++ \\
++\end{array}$ & $\begin{array}{l}+(600) \\
+(450) \\
+++ \\
+++ \\
+++\end{array}$ & $\begin{array}{c}+(600) \\
+++ \\
+++ \\
+++ \\
++++\end{array}$ \\
\hline GL8 & $\begin{array}{l}\text { Control } \\
0.25 \% \\
0.5 \% \\
1.0 \% \\
1.5 \%\end{array}$ & $\begin{array}{l}+(\mathbf{1 7 4}) \\
+(\mathbf{4 8 )} \\
+(\mathbf{1 1 1}) \\
+(\mathbf{5 2 4}) \\
+(\mathbf{7 5})\end{array}$ & $\begin{array}{l}+(\mathbf{1 7 4}) \\
+(\mathbf{4 5 )} \\
+(\mathbf{3 0}) \\
+(\mathbf{3 6}) \\
+(\mathbf{4 6 )}\end{array}$ & $\begin{array}{l}+(\mathbf{( 1 7 4 )} \\
+(\mathbf{6 7}) \\
+(\mathbf{( 2 0 )} \\
+(\mathbf{3 8 0}) \\
+++\end{array}$ \\
\hline ADA & $\begin{array}{l}\text { Control } \\
0.25 \% \\
0.5 \% \\
1.0 \% \\
1.5 \%\end{array}$ & $\begin{array}{l}+(400) \\
+(10) \\
+(24) \\
+(68) \\
+(67)\end{array}$ & $\begin{array}{l}+(400) \\
+(7) \\
+(8) \\
+(9) \\
+(2)\end{array}$ & $\begin{array}{l}+(\mathbf{4 0 0 )} \\
+(\mathbf{4 8 0}) \\
+(15) \\
+(\mathbf{2 0 2}) \\
+(\mathbf{5 4})\end{array}$ \\
\hline
\end{tabular}

The explanation of the symbols is given in Table 2.

respectively whereas the L-enantiomorph had little effect even when present in concentrations as high as $1 \%$.

The next question concerned the influence of an amino acid with $\mathrm{L}$-inducing property on the growth of already existing L-colonies. It appeared that replating L-structures induced in the presence of glycine for example, was fully practicable and these structures preserved their viability. But the number of L-phase colonies growing from equal amounts of diluted ground agar containing L-colony particles and replated in pour plates was decidedly higher in plates containing the basal medium (1000 units penicillin/ml.) without added glycine as compared with others containing even moderate concentrations of glycine. It was concluded that the action of glycine, and probably of other amino acids, had no growth-promoting effect on the L-phase, but was restricted to its L-inducing effect on the cocci, as might be expected because of the high concentrations of the substances required to produce the phenomenon.

In view of the work of Ciak \& Hahn (1959), the possibility was considered of inducing the L-phase of group A $\beta$-haemolytic streptococci with D-cycloserine. It was found when growing the AED strain on the basal medium that the mere replacement of penicillin by D-cycloserine $(3 \mathrm{mg}$./trough) allowed the growth of 5-10 small L-phase colonies in the zone of inhibition. When, however, glycine or DL-serine was added to the medium, the yield of L-phase colonies of the same strain was comparable with that obtained normally with penicillin and these amino acids. The effect of $\mathrm{D}$-cycloserine alone was thus inferior to the action of penicillin; but upon addition of glycine or DL-serine D-cycloserine showed comparable activity to 
penicillin. Penicillin has hitherto been the sole antibiotic found suitable for the isolation of $L$-structures. Now it is shown that $D$-cycloserine can produce the same phenomenon, especially in the presence of some amino acids. It also appeared feasible though difficult to propagate the L-phase colonies obtained with D-cycloserine to a maximum of $1000 \mu \mathrm{g}$. $/ \mathrm{ml}$. The minimal inhibitory concentration for the coccal form of the AED strain was assessed at $250 \mu \mathrm{g}$. D-cycloserine/ml., which corresponds to the concentration found by Ciak \& Hahn (1959) for the group A Richards strain of streptococcus.

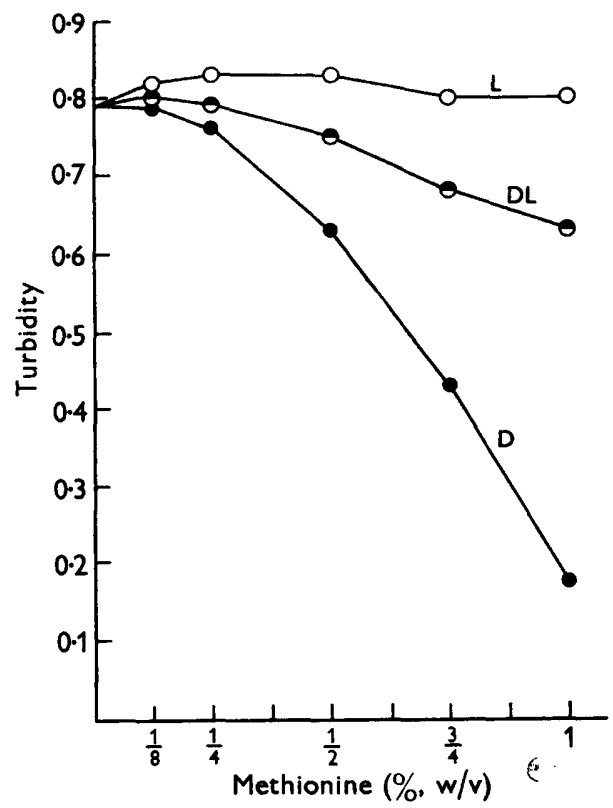

Fig. 1. Influence of the racemate and both the isomers of methionine on the growth of group A $\beta$-haemolytic streptococci. Equal inocula of an $18 \mathrm{hr}$. broth culture of the AED strain were grown in Heart Brain Infusion (Difco) enriched with $10 \%(v / v)$ horse serum. Growth variations caused by different concentrations of the three substances were evaluated as turbidity readings at maximal growth, with a Unicam Spectrophotometer at a wavelength of $550 \mathrm{~m} \mu$. Maximal growth of the cells in this rich medium was obtained after about $14 \mathrm{hr}$. incubation at $37^{\circ} . \odot-O, \mathrm{DL}-\mathrm{Methionine;} \mathrm{O}-\mathrm{O}$, L-methionine; $\longrightarrow$ D-methionine.

Table 6. Effect of the addition of varying concentrations of the racemate and both the isomers of methionine on the yield of $L$-phase colonies in one strain of group $A$ B-haemolytic streptococci

Strain DL-Methionine

L-Methionine
$+(600)$
$+(1)$
$+(1)$
$+(4)$
$+(3)$

$$
\begin{gathered}
\text { D-Methionine } \\
+(600) \\
+++ \\
++++ \\
+++ \\
+++
\end{gathered}
$$$$
+++
$$$$
++
$$$$
+++
$$

The explanation of the symbols is given in Table 2. 


\section{DISCUSSION}

The L-phase inducing property of glycine as described by Dienes \& Zamecnik (1952) with Haemophilus influenzae and Salmonella typhimurium, does not seem to apply to group A $\beta$-haemolytic streptococci. Nevertheless, glycine cannot be considered entirely devoid of this property with group A streptococci, as the number of L-phase colonies increased about twenty-fold or more with all the strains examined, when glycine was added to the basal medium (containing penicillin). The same additive principle was found to be true for serine, threonine, methionine and alanine, and it was further shown that the $\mathrm{D}$-isomers of these amino acids were responsible for this effect. It is not unlikely that other amino acids will be shown active in this respect, although the low solubility of many of them severely limits further experiments, as high concentrations in general were required to elicit the phenomenon. However, the fact that in most cases the $D$-isomers were active in the lowest concentrations tested must be considered an advantage.

Dienes \& Zamecnik (1952) mentioned that the L-inducing capacity of amino acids was always found at bacterial inhibitory concentrations and this finding could be confirmed in our studies. When optical isomers were tested the bacterial growth was not influenced by the L-enantiomorph nor did the L-phase colonies arise in its presence. The yield of L-phase colonies, however, increased when bacterial growth was inhibited by the presence of either the racemate or the D-isomer. The streptococcus strain AED formed an exception and showed in addition a moderate increase of $L$-phase colonies in the presence of $L$-threonine and $L$-alanine. If the view is accepted that a degree of bacterial inhibition by amino acids favours L-type growth induction it could be of value to examine whether the inhibitory influence of the three configurations of several amino acids on the growth of different streptococcal strains is liable to variability. This would give a ready explanation for deviations from the general rule such as were found in the AED strain.

References to the growth-inhibitory effect of amino acids in high concentrations are scarce in the literature. Fling \& Fox (1945) examined the inhibitory action of the racemate and both the isomers of valine, leucine and alanine at $2 \%(w / v)$ with Lactobacillus arabinosus. The effect on growth exhibited the same pattern as was found here with methionine in group $\mathbf{A} \beta$-haemolytic streptococci. D-Alanine however, did not inhibit growth. Gordon \& McLeod (1926) also reported that D-alanine did not influence growth in different species at various concentrations up to $1 \%$. Though these findings seem in contradiction in the first instance with the foregoing, it is possible that the deviating pattern for alanine has some, as yet unknown relation, to the quantitatively exceptional position which this amino acid occupies in streptococcus. In accordance with this hypothesis, the increase of L-phase structures obtained with alanine was found to be less striking, and perhaps associated with higher concentrations than in the case of the other amino acids tested.

Attention was especially focused on D-amino acids, since they were identified as fractions of peptides with antibiotic property. In discussing this subject, Work (1948) gave plausible reasons for the difference in antibiotic activity of D-amino acids as a part of such peptides and as pure substances. As already stated, some D-amino acids can in fact exhibit antibiotic activity provided that their concentration 
has been raised sufficiently. The activity of the amino acids in the present experiments can also be related exclusively to an enhancement of the action of the antibiotic present, and the fact that growth of L-structures arises at concentrations which inhibit bacterial growth denotes the relative insensitivity of the L-phase structures for these substances compared with the coccal form. The possible practical implications of these findings will not be discussed here. That the insensitivity of the L-phase structures to glycine is relative could be shown by the higher yields of subcultures in the basal medium as compared with propagation in the presence of additional glycine.

L-phase colonies and protoplasts have been defined as cell structures which are devoid of their cell walls. This view has received confirmation by chemical and serological studies of group A $\beta$-haemolytic streptococci (Sharp, Hijmans \& Dienes, 1957) and other species as reviewed by Roberts, McQuillen \& Roberts (1959). The accumulation of a $\mathrm{N}$-acetylamino sugar precursor of cell walls of Staphylococcus aureus incubated with penicillin was reported by Park \& Strominger (1957), and explained as a consequence of deficient cell-wall formation following the action of the antibiotic. From this, L-forms and spheroplasts can be also defined as biologically independent cell structures which arise by selective inhibition of cell wall synthesis. Until now the degree of selectivity exhibited by penicillin has not been equalled.

If other substances can provoke the accumulation of compounds similar to those isolated by Park \& Strominger (1957), the possibility of inducing L-structures and spheroplasts with these arises, provided they are not toxic to the remaining structures. Accumulation of the cell-wall precursor compound was demonstrated with, in addition to penicillin, bacitracin, glycine, and oxytetracycline by Park (1958), and with D-cycloserine by Ciak \& Hahn (1959).

It is very likely that the reverse will also be true, i.e. substances that can give rise to L-phase structures and spheroplasts will appear to accumulate the cell-wall precursor. Therefore the isolation of 'protoplasts' with several amino acids by Welsch (1958), with D-amino acids by Lark \& Lark (1958) and the present findings on L-phase structures, strongly suggest that several $\mathbf{D}$-amino acids can be added to the substances already mentioned.

In this connexion, it seems worth mentioning that while the L-inducing property of D-cycloserine was very weak and that of glycine absent, the substances in combination induced a great many fully grown L-structures. It is suggested that the morphological effects resulting from this additive phenomenon will also be reflected at a biochemical level. The effective range of $\mathrm{D}$-cycloserine for the propagation of L-structures seems to be as narrow as for many other antibiotics (Ward, Madoff \& Dienes, 1958).

The authors wish to express their thanks to Professor M. Welsch (Liège) and Dr P. G. de Haan (Utrecht) for their helpful discussions during this work. Acknowledgement is also due to Dr C. E. de Moor (Utrecht) for the typing of the streptococcal strains of local origin. D-Cycloserine was a gift from Hoffmann-La Roche A.G. (Basel). 


\section{REFERENCES}

Brenner, S., Dark, F. A., Gerhardt, P., Jeynes, M. H., Kandler, O., Kellenberger, E., Kuteneberger-Nobel, E., McQuillen, K., Rubio-Huertos, M., Salton, M. R. J., Strange, R. E., Tomcsik, J. \& Weibull, C. (1958). Bacterial protoplasts. Nature, Lond. 181, 1713.

Crak, J. \& Hahn, F. E. (1959). Mechanisms of action of antibiotics. II. Studies on the mode of action of cycloserine and its L-isomer. Antibiot. and Chemother. 9, 47.

Cummins, C. S. \& Harris, H. (1956). The chemical composition of the cell wall in some Gram-positive bacteria and its possible value as a taxonomic character. J. gen. Microbiol. 14, 583.

Dienes, L. \& Weinberger, H. J. (1951). The L-forms of bacteria. Bact. Rev. 15, 245.

Drenes, L. \& Zamecnik, P. C. (1952). Transformation of bacteria into L-forms, by amino acids. J. Bact. 64, 770.

Fuing, M. \& Fox, S. W. (1945). Antipodal specificity in the inhibition of growth of Lactobacillus arabinosus by amino acids. J. biol. Chem. 160, 329.

Fortner, J. (1928). Ein einfaches Plattenverfahren zur Züchtung strenger Anaerobier. Zbl. Bakt. I (Abt. Orig.), 108, 155.

Gordon, J. \& McLEod, J. W. (1926). Inhibition of bacterial growth by some amino acids and its bearing on the use of tryptic digests as culture media. J. Path. Bact. 29, 13.

Gordon, J. \& Gondon, M. (1943). Involution forms of the genus Vibrio produced by glycine. J. Path. Bact. 55, 63.

Gordon, J., Hall, R. A. \& Stickland, L. H. (1949). A comparison of the degree of lysis by glycine of normal and glycine resistant organisms. J. Path. Bact. 61, 581.

Hayashi, J. A. \& Barkulis, S. S. (1959). Studies of streptococcal cell walls. III. The amino acids of the trypsin-treated cell wall. J. Bact. 77, 177.

LARK, C. \& LARK, K. G. (1958). Induction of protoplast-like structures in bacteria by D-amino acids. Proc. Soc. Amer. Bact. 58, 108.

Maculla, E. S. \& Cowles, P. B. (1948). The use of glycine in the disruption of bacterial cells. Science, $107,376$.

McQuiluen, K. (1959). Colloquium on the growth chemistry of homofermenting bacteria. Proc. 4th Int. Congr. Biochem. 13, 363.

Park, J. T. \& Strominger, J. L. (1957). Mode of action of penicillin. Science, 125, 99.

PArK, J. T. (1958). Inhibition of cell wall synthesis in staphylococcus aureus by chemicals which cause accumulation of wall precursors. Biochem. J. 70, 2 P.

Pierce, C. (1942). Streptobacillus moniliformis, its associated L-form and other Pleuropneumonia-like organisms. J. Bact. 43, 780 (Abstr.).

Roberts, R. B., MCQUILuen, K. \& Roberts, I. Z. (1959). Biosynthetic aspects of metabolism. Annu. Rev. Microbiol. 13, 1.

SaLton, M. R. J. (1953). Studies of the bacterial cell wall. IV. Composition of the cell walls of some Gram-positive and Gram-negative bacteria. Biochim. biophys. Acta, 10, 512.

Sharp, J. T. (1954). L-Colonies from $\beta$-hemolytic streptococci. New technic in the study of L-forms of bacteria. Proc. Soc. exp. Biol., N.Y. 87, 94.

Sharp, J. T., Hijmans, W. \& Dienes, L. (1957). Examination of the L-forms of group A streptococci for the group-specific polysaccharide and M protein. J. exp. Med. 105, 153.

WARD, J. R., MAdoff, S. \& DIENEs, L. (1958). In vitro sensitivity of some bacteria, their L-form and Pleuropneumonia-like organisms to antibiotics. Proc. Soc. exp. Biol., N.Y. 97, 132.

WeLsch, M. (1958). Formation de protoplastes d'Escherichia coli sous l'inftuence de la glycine et d'autres acides aminés. Schreiz. Z. allg. Path. 21, 741.

Work, T. S. (1948). In: The relation of optical form to biological activity in the amino acid series. Symp. Biochem. Soc. 1. 


\section{EXPLANATION OF PLATE 1}

Quarters of photographs of four plates are assembled to represent the influence of increasing con-

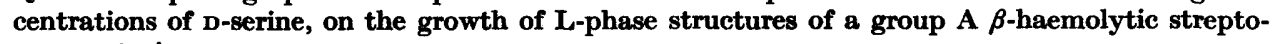
coccus strain.

The left upper quadrant represents the zone of inhibition obtained with penicillin when the B 6 strain was cultured in the basal medium. Some L-phase colonies can be distinguished in the inner zone of bacterial growth.

The next quarters are ordered clockwise. The corresponding plates contained in addition to the basal medium, $0.5,1$, and $1.5 \%$ D-serine respectively. The huge increase of L-phase growth and decrease of bacterial growth in the same strain, caused by the increase of the concentration of the amino acid, is clearly demonstrated.

A peculiarity of L-phase growth of the B6 strain was the diffusion of an unknown brownish substance from the colonies into the surrounding agar. This explains the whitish and rather vague circumference shown by many L-phase colonies of large size. 

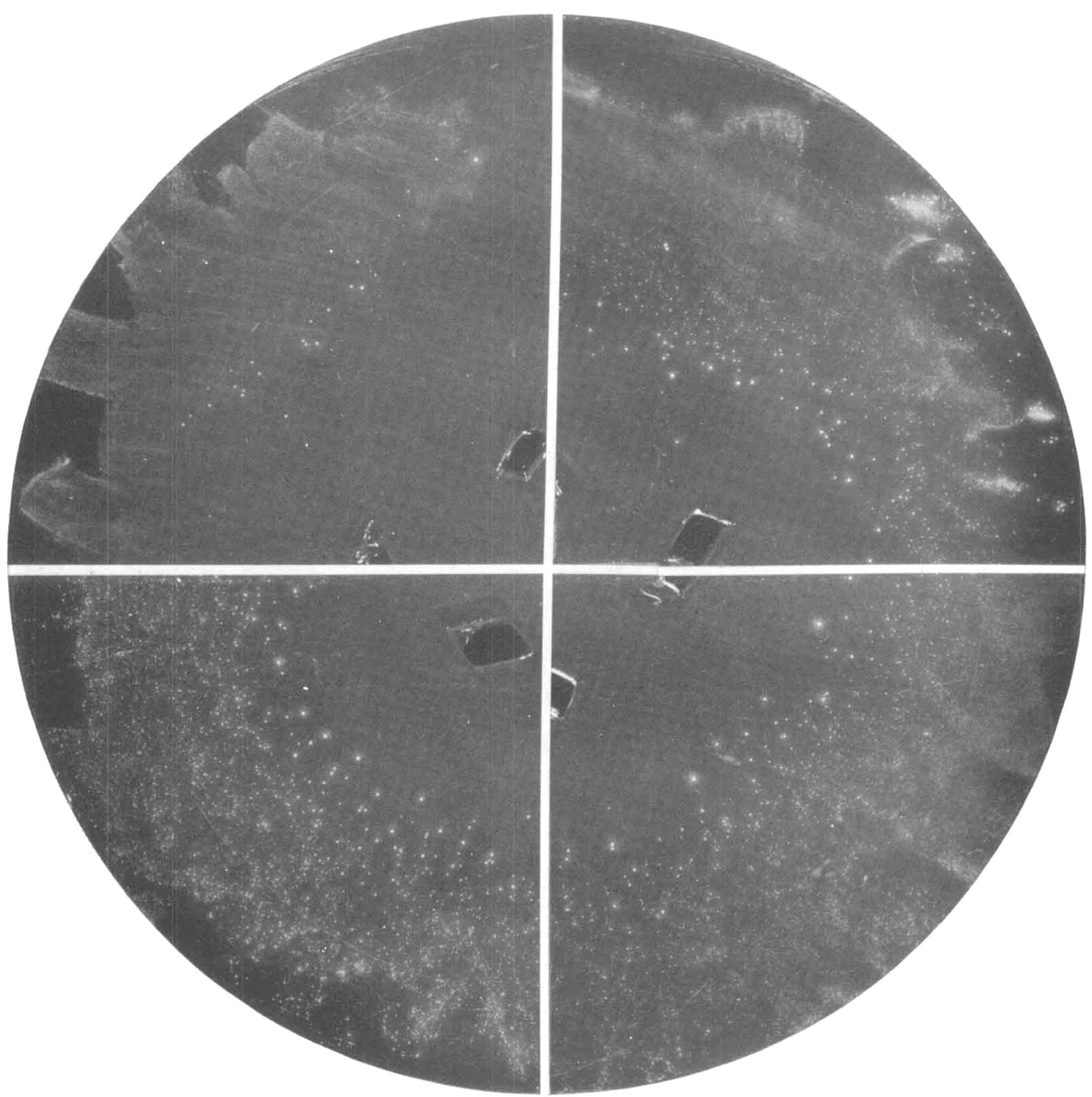

M. F. MICHEL AND W. HIJMANS 